\title{
Adição de flocos de aveia (Avena sativa l.) na elaboração de massa de pizza: avaliação físico-química e sensorial
}

\author{
Addition of rolled oats (Avena sativa I.) in the preparation of pizza dough: \\ physicochemical and sensory evaluation
}

\author{
Ângela Moraes Teixeira' \\ Kriscia Maria Prestes Campos ${ }^{2}$ \\ José Raniere Mazile Vidal Bezerra ${ }^{3}$ \\ Maurício $\operatorname{Rigo}^{4}(*)$
}

\section{Resumo}

A aveia é um cereal que apresenta um alto teor de fibras solúveis e de proteínas, auxiliando na redução de riscos de algumas enfermidades. Por isso pode ser adicionada em formulações alimentícias devido à suas características nutritivas e saudáveis. A adição de flocos de aveia em pizzas poderia ser uma alternativa interessante, devido ao aumento do consumo de pizzas em função da sua praticidade, baixo custo, sabor agradável e valor nutritivo. Este trabalho teve como objetivo elaborar uma massa de pizza com adição de flocos de aveia, visando à obtenção de um produto benéfico à saúde e o enriquecimento do valor nutricional da massa. Foram testadas formulações com 10\%, $20 \%$ e $30 \%$ de flocos de aveia na massa de pizza. Testes sensoriais de aceitação foram realizados para avaliar a aparência, sabor, aroma e textura do produto. Os resultados obtidos apontam que é viável a comercialização da massa de pizza com flocos de aveia no mercado, sendo que não houve diferença significativa entre as amostras e os valores das médias para todos os atributos corresponderam a gostei muito na escala hedônica utilizada. A composição química das formulações padrão e com $30 \%$ de flocos de aveia da massa de pizza foi: umidade 31,91 e 31,66\%; fibras 1,52 e 1,73; cinzas 1,51 e 1,64\%; proteínas 12,77 e 14,36\%; lipídios 1,14 e 1,05\%, respectivamente.

Palavras-Chave: aceitação sensorial; escala hedônica; disco de massa fermentada.

1 Dra.; Tecnologia de Alimentos; Universidade Estadual de Campinas, UNICAMP, Brasil; Professora na Universidade Estadual do Centro-Oeste; Endereço: Universidade Estadual do Centro-Oeste. Simeão Camargo Varela de Sá, 03, Vila Carli. CEP: 85040080 - Guarapuava, PR - Brasil; E-Mail:

2 Engenheira de Alimentos. Universidade Estadual do Centro-Oeste, UNICENTRO, Brasil; Atuou na área de pesquisa em 2013-2014, no programa de I.C - Iniciação Científica, seu projeto inclui massas enriquecidas com fibras; Endereço: Universidade Estadual do Centro-Oeste. Simeão Camargo Varela de Sá, 03, Vila Carli. CEP: 85040080 - Guarapuava, PR - Brasil; E-Mail:

3 Dr.; Engenharia de Alimentos; Universidade Estadual de Campinas, UNICAMP, Brasil; Professor Associado "C" do Departamento de Engenharia de Alimentos da Universidade Estadual do Centro-Oeste (UNICENTRO); Endereço: Universidade Estadual do Centro-Oeste, Setor de Ciências Exatas e de Tecnologia. Rua:Pres. Zacarias, 875, Santa Cruz. CEP: 85010990 - Guarapuava, PR - Brasil E-Mail:

4 Dr.; Engenharia de Alimentos; Universidade Estadual de Campinas, UNICAMP, Brasil; professor do Curso de Engenharia de Alimentos da Universidade Estadual do Centro-Oeste (UNICENTRO); Endereço: Universidade Estadual do Centro-Oeste, Departamento de Engenharia de Alimentos. Rua Simeão Varela Camargo de Sá, 03, Vila Carli. CEP: 85040080 - Guarapuava, PR - Brasil E-Mail: (*) Autor para correspondências

\begin{tabular}{llllll}
\hline Ambiência & Guarapuava (PR) & v.14 n.2 & p. 390-400 & Maio/Ago 2018 & ISSN $1808-0251$
\end{tabular}




\section{Abstract}

Oats are a cereal that besides having a high content of soluble fiber, also has high level of proteins, helping to reduce the risk of some diseases. So it makes it a nutritious and healthy complement to food. And the pizza is an interesting target for use of this cereal. Since the consumption of pizzas has increased due to product convenience and low cost, pleasant taste and nutritional value. This study aimed to prepare a pizza dough with the addition of oatmeal, aimed at obtaining a product beneficial to health and enrich the nutritional value of dough. Formulations with 10\%, 20\% and 30\% oat flakes in the pizza dough were tested. acceptance of sensory tests were conducted to evaluate the appearance, taste, aroma and texture of the product. The results show that the marketing of pizza dough with oat flakes on the market is viable and that there was no significant difference between the samples and the mean values for all attributes corresponding to liked the hedonic scale used. The chemical composition of standard formulations and with 30\% oat flakes pizza dough was: Moisture 31.91\% and 31.66\%; fibers 1,52 and 1,73 ; ashes $1.51 \%$ and $1.64 \%$; protein 12,77 and $14,36 \%$, lipids $1.14 \%$ and $1.05 \%$; respectively.

Key words:sensory acceptance; hedonic scale; disk of dough leavened.

\section{Introdução}

As tendências da alimentação mundial de alimentos, com base em uma análise de relatórios estratégicos produzidos por institutos de referência, agrupam-se em cinco categorias: sensorialidade e prazer, saudabilidade e bem-estar, conveniência e praticidade, confiabilidade e qualidade e sustentabilidade e ética (BARBOSA et al., 2010).

O crescente número de consumidores esclarecidos quanto ao papel da alimentação em sua saúde vem estimulando a indústria a desenvolver alimentos reformulados em relação aos seus similares convencionais e que detenham alguma melhora nutricional (QUEIROZ et al., 2014). A ANVISA denomina os alimentos contendo substâncias especiais do ponto de vista de saúde como "Alimentos com Alegações de Propriedade Funcional e/ou de Saúde". A aveia é um exemplo de fonte de fibra solúvel com ações positivas sobre a saúde cardiovascular e com potencial para aplicação no setor de panificação e confeitaria (ALVIM et al., 2014).

A aveia está disponível para o consumidor na forma de farinha e flocos finos. Tem sido empregada pela indústria de alimentos na produção de alimentos infantis, shakes, smoothies, massas, sopas, suplementos alimentares, granola, muslins, barra de cereais, pães, biscoitos, bolos e ingrediente para engrossar sopas, molhos e para aumentar o volume de produtos cárneos.

Segundo Webster (1986) citado por GUTKOSKI e PEDÓ (2000), a aveia destaca-se dentre os outros cereais por seu teor e qualidade proteica, variando de 12,4 a $24,5 \%$ no grão descascado; e por sua maior porcentagem de lipídios, que varia de 3,1 a 10,9\%, distribuídos por todo o grão e com predominância de ácidos graxos insaturados.

O cereal também se destaca por seu teor de fibras alimentares e, principalmente, pela concentração de beta-glucanas, componentes estruturais das paredes celulares dos cereais, que atuam na redução do colesterol em indivíduos com hipercolesterolemia, conforme demonstrado por estudos clínicos sobre os efeitos de aveia e farelo de aveia na redução do colesterol sérico e na consequente diminuição dos riscos de doenças coronárias (FDA, 1997). 
No Brasil, ao final do século 19 se difundiu a pizza devido à imigração italiana, e é considerada hoje um dos alimentos mais populares do país. Porém, a qualidade da sua massa continua sendo uma área pouco explorada se comparada a outros produtos de forno (WANG et al., 2005).

Segundo MATHEWASON (2000) a pizza é definida de modo semelhante ao pão: um produto com a consistência esponjosa, resultado do cozimento da massa de levedura fermentada, obtida a partir da mistura de farinha de trigo, água, sal, e outros ingredientes se necessário'.

A pizza é um produto de custo baixo, preparo rápido, sabor agradável e valor nutritivo consideravelmente alto, nos dias de hoje é um dos produtos mundialmente mais consumidos.

A massa da pizza forma uma fração significativa do produto e, aparência, sabor e textura são fatores importantes para sua identificação e aceitação pelo consumidor (LARSEN et al., 1993).

O presente trabalho teve como objetivos estudar formulações de massa de pizza com flocos de aveia, avaliar as propriedades físico-químicas das formulações e realizar testes sensoriais, buscando conhecer a aceitação do produto final, como uma opção mais nutritiva para os consumidores de Guarapuava, PR, Brasil.

\section{Material e Métodos}

\section{Material}

A farinha de trigo, flocos finos de aveia, fermento biológico seco e sal utilizados nas formulações de massa de pizza foram obtidos no comércio local de Guarapuava, PR, Brasil.

As análises foram feitas no Laboratório de Análise de Alimentos e de Análise Sensorial da Universidade Estadual do Centro-Oeste, em Guarapuava, PR, Brasil.

\section{Formulações das pizzas}

As formulações foram desenvolvidas por meio de pré-testes em laboratório, utilizando como base uma receita convencional de massa de pizza. Foram preparadas quatro formulações de massas para pizza, uma sem adição (Padrão) e três com adição de diferentes quantidades de flocos finos de aveia (F10; F20; F30), variando-se as proporções entre os ingredientes conforme a Tabela 1 . Os discos de pizza foram pré-assados por 10 minutos a $180^{\circ} \mathrm{C}$. Após resfriamento as massas foram embaladas em sacos de polipropileno e acondicionadas sob refrigeração.

Tabela 1. Formulações de massa de pizza com flocos finos de aveia.

\begin{tabular}{ccccc}
\hline $\begin{array}{c}\text { Ingredientes } \\
\left(\mathbf{g} \mathbf{1 0 0} \mathbf{~ g}^{-\mathbf{1}}\right)\end{array}$ & Padrão & $\mathbf{F 1 0}$ & $\mathbf{F 2 0}$ & $\mathbf{F 3 0}$ \\
\hline Farinha de trigo comum & 66 & 56 & 46 & 36 \\
Flocos finos de aveia & & 10 & 20 & 30 \\
Fermento biológico & 0,6 & 0,6 & 0,6 & 0,6 \\
Sal & 0,4 & 0,4 & 0,4 & 0,4 \\
Água & 33 & 33 & 33 & 33 \\
Total & 100 & 100 & 100 & 100 \\
\hline
\end{tabular}

Fonte: Teixeira et al. (2016).

Nota: Padrão - Formulação padrão sem adição de flocos de aveia; F10 - Formulação com 10\% de flocos de aveia; F20 - Formulação com $20 \%$ de flocos de aveia; F3 - Formulação com 30\% de flocos de aveia. 


\section{Avaliação Química}

A determinação de umidade foi realizada em estufa a $105^{\circ} \mathrm{C}$ até peso constante. $\mathrm{O}$ teor de cinzas foi obtido por meio da incineração em mufla a $550{ }^{\circ} \mathrm{C}$ por 5 h. A proteína bruta foi determinada pelo método de Kjeldahl ( $\mathrm{N}$ x 5,70). O teor de lipídios foi determinado pelo método de Soxhlet. As análises foram realizadas de acordo com as Normas Analíticas do Instituto Adolfo Lutz (IAL 2008), em triplicata.

A fibra alimentar foi determinada por cálculo, utilizando-se dados das tabelas de composição nutricional informada nos rótulos das embalagens de aveia em flocos finos e farinha de trigo. Já para os carboidratos foi realizado o cálculo da diferença entre $100 \mathrm{~g}$ do alimento e a soma total dos valores encontrados para umidade, lipídeos, proteínas, cinzas, e fibra alimentar.

\section{Avaliação Sensorial}

O presente estudo foi aprovado pelo Comitê de Ética em Pesquisa da Universidade Estadual do Centro Oeste (CAAE 170722131.0000.0106).

A avaliação sensorial foi realizada na Universidade Estadual do Centro-Oeste do Paraná, com 30 julgadores não treinados no horário de 10 às 12 horas. Foram avaliadas 4 formulações de massa de pizza, a padrão, a com $10 \%$, a com $20 \%$ e outra com $30 \%$ de flocos de aveia. E, a partir do resultado obtido, foi realizada outra análise sensorial das formulações padrão e com 30\% de aveia, no Colégio Estadual Padre Chagas, Guarapuava/PR, com 45 julgadores (estudantes do ensino médio) não treinados no horário de 19 às 21 horas. Foram oferecidas para avaliação porções de massa de pizza com molho de tomate, queijo mussarela e orégano.

As amostras foram colocadas em pratos brancos, codificadas com números de três algarismos (DUTCOSKY, 2007) e oferecidas para os julgadores, junto com um termo de consentimento livre e esclarecido, e a ficha de identificação do perfil do provador (nome, gênero, idade, grau de escolaridade) e a ficha específica de aplicação do teste. Junto com as amostras, os julgadores receberam um copo descartável com água filtrada em temperatura ambiente, para que fosse tomado entre as amostras, que eram provadas da esquerda para direita. A água serve para a limpeza do palato, com o objetivo de melhorar a percepção dos aspectos sensoriais.

O teste sensorial utilizado foi escala hedônica de 9 pontos, ancorada nos extremos gostei muitíssimo (nota 9) e desgostei muitíssimo (nota 1) (IAL, 2008). A escala de intenção de compra utilizada foi a de 5 pontos $(5=$ certamente compraria a $1=$ certamente não compraria).

\section{Análise Estatística}

Os resultados foram apresentados em média \pm desvio padrão e verificados utilizando análise de variância (ANOVA), em seguida o teste de médias de Tukey, com nível de variância de 95\% (ARANGO, 2005). O programa utilizado foi o Statistical Analysis System (SAS). 


\section{Resultados e Discussão}

\section{Avaliação Sensorial}

Os resultados da análise sensorial, executada com julgadores na Universidade Estadual do Centro-Oeste, das formulações de massa de pizzas desenvolvidas no presente trabalho estão apresentados na Tabela 2 , onde pode ser observado que não houve diferença significativa entre as amostras de massa de pizza padrão e formulações com flocos de aveia nas diferentes porcentagens testadas ao nível de 5\% de significância, com relação aos atributos aparência, aroma, sabor e textura. Observando-se os valores das médias verifica-se que a nota predominante 8 corresponde a gostei muito na escala hedônica utilizada para o teste sensorial o que indica uma provável aceitação para as massas de pizza formuladas com 10\%,20\% e 30\% de adição flocos de aveia em substituição parcial da farinha de trigo.

\section{Tabela 2. Valores médios de aceitação dos atributos sensoriais aparência, aroma, sabor e textura das amostras de massa de pizza com diferentes teores de flocos de aveia.}

\begin{tabular}{ccccc}
\hline Formulações & Aparência & Aroma & Sabor & Textura \\
\hline Padrão & $8,2 \pm 0,8^{\mathrm{a}}$ & $8,3 \pm 0,7^{\mathrm{a}}$ & $8,0 \pm 0,8^{\mathrm{a}}$ & $7,7 \pm 0,9^{\mathrm{a}}$ \\
F10 & $8,0 \pm 0,9^{\mathrm{a}}$ & $8,1 \pm 0,7^{\mathrm{a}}$ & $7,9 \pm 0,8^{\mathrm{a}}$ & $7,8 \pm 1,0^{\mathrm{a}}$ \\
F20 & $8,1 \pm 0,8^{\mathrm{a}}$ & $8,0 \pm 0,9^{\mathrm{a}}$ & $8,0 \pm 1,0^{\mathrm{a}}$ & $7,8 \pm 0,8^{\mathrm{a}}$ \\
F30 & $8,0 \pm 1,0^{\mathrm{a}}$ & $8,0 \pm 0,8^{\mathrm{a}}$ & $8,0 \pm 1,0^{\mathrm{a}}$ & $7,8 \pm 1,0^{\mathrm{a}}$ \\
\hline
\end{tabular}

Fonte: Teixeira et al. (2016).

Nota: Padrão - Formulação padrão sem adição de flocos de aveia; F10 - Formulação com 10\% de flocos de aveia; F20 - Formulação com 20\% de flocos de aveia; F3 - Formulação com 30\% de flocos de aveia. Letras diferentes na mesma coluna indicam diferença estatística à $(p \leq 0,05)$, entre as formulações.

\section{Atributo aparência}

Em relação ao atributo aparência, os tratamentos padrão e com 30\% de flocos de aveia foram bem aceitos, não diferindo significativamente entre si $(\mathrm{p} \leq 0,05)$ (Tabela 2). A distribuição das notas de aceitação de cada uma das amostras para o atributo aparência está apresentada na Figura 1. Para os tratamentos houve predomínio de média 8 ("gostei muito") no teste de aceitação, conforme mostrado no histograma.

Observa-se na Figura 1 que não há uma diferença significativa entre as porcentagens de acordo com as notas oferecidas, para a pizza padrão e a formulação com $30 \%$ de flocos finos de aveia.

\section{Atributo aroma}

Observa-se na Figura 1, que não houve uma diferença grande nas porcentagens de acordo com as notas oferecidas, para a pizza padrão e a formulação com $30 \%$ de flocos de aveia. Conforme se pode observar no histograma 56\% dos julgadores atribuíram notas 8 ("gostei muito") e 9 ("gostei muitíssimo") para formulação de massa de pizza com aveia indicando uma ótima aceitação do produto desenvolvido com relação ao aroma (Figura 1). 


\section{Figura 1. Distribuição percentual das notas de aceitação de aparência e aroma das amostras de massa de pizza padrão e com $30 \%$ de flocos de aveia.}
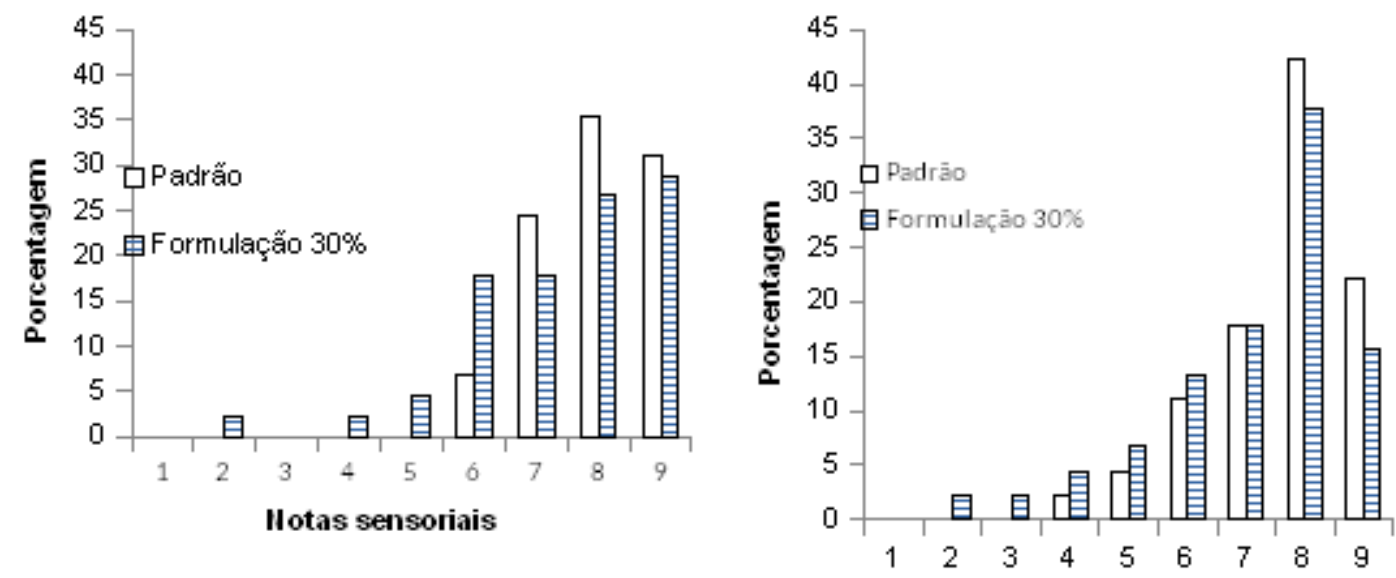

Fonte: Teixeira et al. (2016).

Nota:Escala: 1 = desgostei muitíssimo; 2= desgostei muito; 3= desgostei moderadamente; 4= desgostei ligeiramente; $5=$ nem gostei/nem desgostei; 6= gostei ligeiramente; 7= gostei moderadamente; 8= gostei muito; $9=$ gostei muitíssimo.

\section{Atributo Sabor}

As formulações de massa de pizza com 30\% de flocos de aveia receberam notas entre 7 ("gostei moderadamente") e 9 ("gostei muitíssimo") para o atributo sabor de $80 \%$ dos julgadores conforme pode-se observar na Figura 2. Em relação ao atributo avaliado, os dois tratamentos foram bem aceitos, não diferindo significativamente entre si ( $>>0,05)$ (Tabela 2).

\section{Atributo Textura}

A análise das massas de pizza sem e com a presença de flocos de aveia não apresentou diferença significativa na textura (Tabela 2). Os consumidores gostaram das formulações degustadas indicando que a massa de pizza pode ser incrementada com flocos de aveia na sua formulação. Verifica-se na Figura 2 que as amostras foram bem aceitas em relação a textura. Houve muita pouca diferença para as notas 8 e 9 na comparação da massa padrão com a formulação com $30 \%$ de flocos finos de aveia.

CAMPOS et al. (2014) avaliaram sensorialmente pizza integral com substituição parcial da farinha integral de trigo em teores de 0, 20 e 30\% por farinha de aveia, quinoa e linhaça. As formulações desenvolvidas com 20 e 30\% dos cereais testados proporcionaram pizzas integrais com escores 8 e 7,7 respectivamente de aceitabilidade pelos consumidores. RUSSO et al. (2012) comprovaram através de teste de aceitação sensorial que a adição de até $5 \%$ de farinha de linhaça em massa de pizza pode ser utilizada. Segundo os autores massa de pizza integral com ingredientes que apresentem propriedades funcionais pode ser um produto de excelente potencial para o mercado consumidor. Portanto os resultados reportados por CAMPOS et al. (2014) e RUSSO et al. (2012) corroboram os resultados obtidos neste trabalho, pois as massas de pizzas desenvolvidas com até $30 \%$ de substituição parcial da farinha de trigo por farinha de aveia apresentaram notas médias do teste de aceitação em torno de 8, que significa "gostei muito". 
Figura 2. Distribuição percentual das notas de aceitação do sabor e textura das amostras de massa de pizza padrão e com $30 \%$ de flocos de aveia.
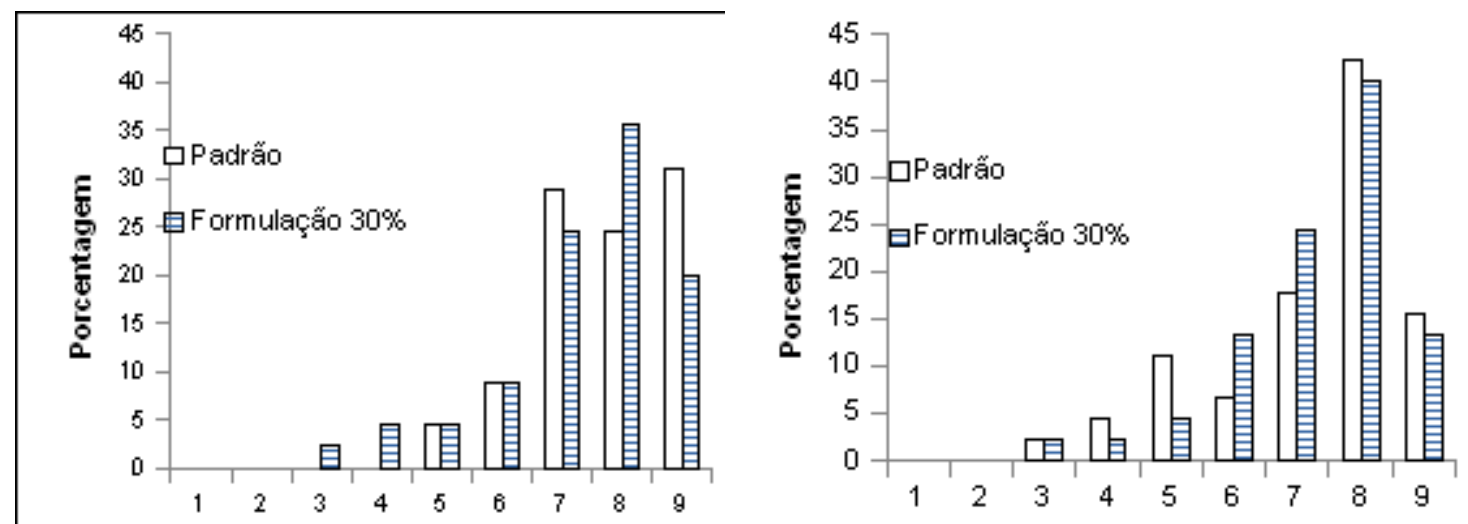

Fonte: Teixeira et al. (2016).

Nota: Escala: 1 = desgostei muitíssimo; 2= desgostei muito; 3= desgostei moderadamente; 4= desgostei ligeiramente; 5= nem gostei/nem desgostei; 6= gostei ligeiramente; 7= gostei moderadamente; 8= gostei muito; 9= gostei muitíssimo.

Como a formulação com 30\% de flocos finos de aveia se mostrou com boa aceitação sensorial e continha maior teor de aveia do que as outras formulações, para a sequencia da investigação sensorial foi realizado teste de aceitação dos tratamentos massa de pizza com $30 \%$ de flocos de aveia e o padrão, avaliando-se os atributos aparência, aroma, sabor e textura, com julgadores no Colégio Estadual Padre Chagas, Guarapuava/PR. As médias deste teste estão apresentadas na Tabela 3.

Os valores da média de aceitação da Tabela 3 corroboram os resultados do teste de aceitação da Tabela 2, pois em ambos os testes não houve diferença significativa entre as amostras de massa de pizza padrão e com 30\% de flocos de aveia ao nível de 5\% de significância com relação aos atributos aparência, aroma, sabor e textura. Entretanto os valores das médias variou entre 7 e 8 , o que corresponde ao intervalo da escala hedônica de "gostei moderadamente e gostei muito", o que evidencia uma boa aceitação para a massa de pizza formulada com 30\% de flocos de aveia.

Tabela 3. Valores médios de aceitação das amostras de massa de pizza padrão e com $30 \%$ de flocos de aveia.

\begin{tabular}{ccccc}
\hline Formulações & Aparência & Aroma & Sabor & Textura \\
\hline Padrão & $7,6^{\mathrm{a}}$ & $7,7^{\mathrm{a}}$ & $7,7^{\mathrm{a}}$ & $7,2^{\mathrm{a}}$ \\
F30 & $7,0^{\mathrm{a}}$ & $7,4^{\mathrm{a}}$ & $7,3^{\mathrm{a}}$ & $7,3^{\mathrm{a}}$ \\
\hline
\end{tabular}

Fonte: Teixeira et al. (2016).

Nota: Padrão - Formulação padrão sem adição de flocos de aveia; F3 - Formulação com 30\% de flocos de aveia. Letras diferentes na mesma coluna indicam diferença estatística à ( $p \leq 0,05)$, entre as formulações. 


\section{Intenção de compra}

As notas atribuídas pelos provadores para a intenção de compra das massas de pizzas padrão e com adição de 30 \% de aveia estão apresentadas na Figura 3, onde os valores encontrados para a intenção de compra para as duas formulações mostram uma tendência semelhante dos valores, sendo que aproximadamente $20 \%$ dos julgadores atribuíram nota 1 "certamente não compraria" para ambas as amostras, e $78 \%$ dos provadores certamente comprariam as duas amostras avaliadas (nota 5), concluindo que as amostras tiveram baixa rejeição e alto índice de aprovação. A atitude positiva dos consumidores quanto à intenção de compra demonstra que se o produto formulado com flocos de aveia fosse disponibilizado para a venda o potencial de aceitação seria elevado.

\section{Figura 3. Valores atribuídos à intenção de compra das massas de pizza formuladas.}

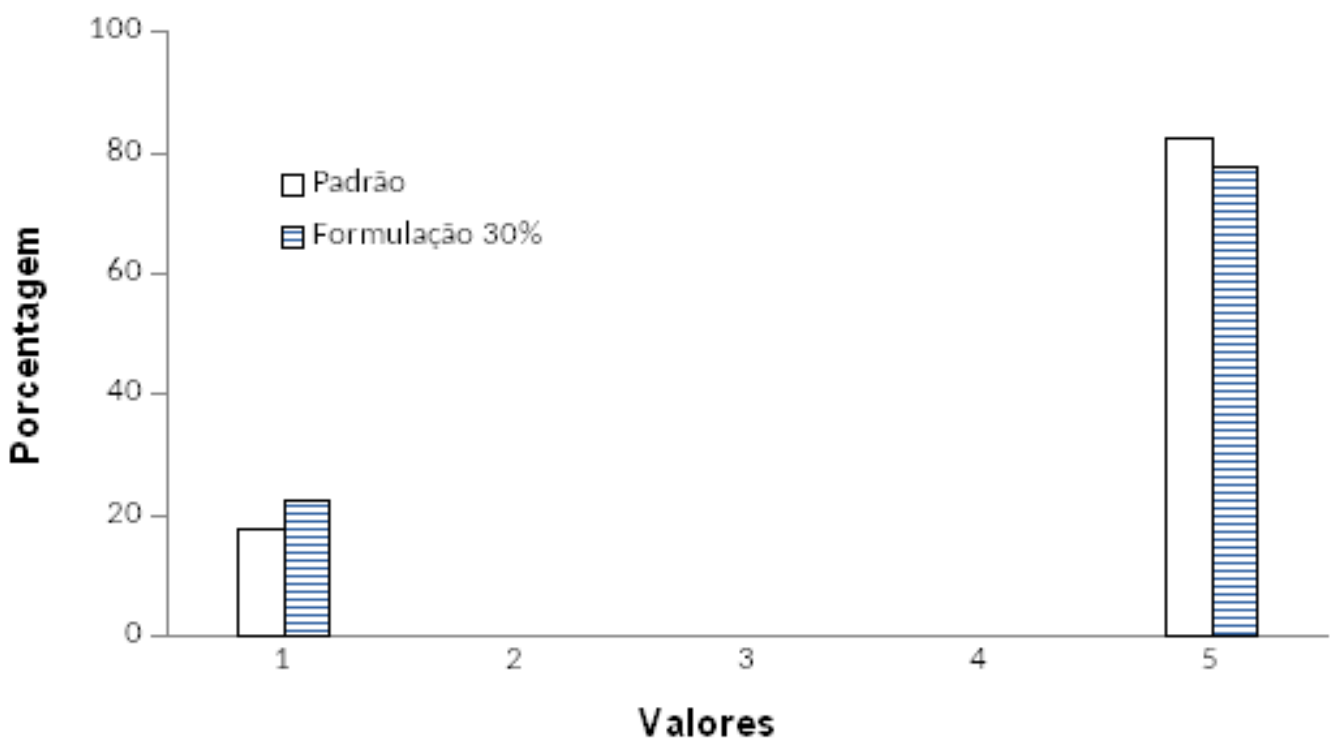

Fonte: Teixeira et al. (2016).

Nota:Escala: $1=$ certamente não compraria; 2=possivelmente não compraria; $3=$ talvez comprasse; talvez não comprasse; $4=$ possivelmente compraria; $5=$ certamente compraria.

\section{Avaliação Química}

Para determinação da composição química foram escolhidas as formulações de massa de pizza padrão e a adicionada com 30\% de flocos de aveia, pois essa última apresentou altas notas na avaliação sensorial e continha o maior teor de aveia dentre as formulações investigadas. Os resultados obtidos estão apresentados na Tabela 4.

A substituição parcial da farinha de trigo por $30 \%$ de flocos de aveia nas massas de pizzas resultou em um aumento do teor de fibras e cinzas, e um decréscimo no teor de carboidratos e lipídeos, mas sem apresentar diferença estatística a um nível de significância de 5\%.Já a formulação com 30\% de aveia apresentou maior teor de proteína do que a formulação padrão ao nível de significância de 5\%. Esse resultado era esperado, pois a aveia empregada nas formulações tinha teor de proteína de 14,3\% (segundo informação do rótulo da embalagem), enquanto o trigo tinha teor de proteína de 9,8\% (TACO, 2011). 


\section{Tabela 4- Composição centesimal das formulações de massa de pizza padrão e a adicionada com $30 \%$ de flocos de aveia.}

\begin{tabular}{ccc}
\hline Componentes & \multicolumn{2}{c}{ Formulações } \\
\hline$\left(\mathrm{g} 100 \mathrm{~g}^{-1}\right)$ & Padrão & F30 \\
Umidade & $31,91 \pm 0,37^{\mathrm{a}}$ & $31,66 \pm 0,28^{\mathrm{a}}$ \\
Cinzas & $1,51 \pm 0,02^{\mathrm{a}}$ & $1,64 \pm 0,03^{\mathrm{a}}$ \\
Proteínas & $12,77 \pm 0,13^{\mathrm{a}}$ & $14,36 \pm 0,21^{\mathrm{b}}$ \\
Lipídeos & $1,14 \pm 0,28^{\mathrm{a}}$ & $1,05 \pm 0,37^{\mathrm{a}}$ \\
Fibras alimentar & $1,52 \pm 0,18^{\mathrm{a}}$ & $1,73 \pm 0,24^{\mathrm{a}}$ \\
Carboidratos & $52,25 \pm 1,13^{\mathrm{a}}$ & $49,56 \pm 1,38^{\mathrm{b}}$ \\
\hline
\end{tabular}

Fonte: Teixeira et al. (2016).

Nota: Padrão - Formulação padrão sem adição de flocos de aveia; F3 - Formulação com 30\% de flocos de aveia. Médias com letras iguais na mesma linha indicam não haver diferença significativa entre os resultados $(p \leq 0,05)$, pelo teste de Tukey.

A Agência Nacional de Vigilância Sanitária (Brasil, 2000) prescreve que para massa alimentícia úmida ou fresca, o produto final deve apresentar umidade máxima de $35 \%$. As formulações padrão e com adição de flocos finos de aveia atenderam a essa condição.

Yongs e colaboradores (1985), afirmam que a aveia é o cereal que apresenta um dos maiores teores de proteínas. A proteína da aveia distingue-se pelo seu alto teor de arginina em relação aos outros cereais. Os resultados obtidos neste trabalho mostraram que houve um ligeiro aumento no teor de proteína na formulação com $30 \%$ de flocos de aveia em relação à massa de pizza controle.

\section{Conclusões}

De modo geral, os resultados obtidos para as massas de pizza contendo flocos de aveia foram considerados satisfatórios, quando comparados à formulação padrão contendo apenas farinha de trigo, pois a presença de $30 \%$ aveia na formulação promoveu um ligeiro aumento no teor de proteína do produto.

Não houve diferença significativa entre as diferentes formulações de massa de pizza com relação aos atributos sensoriais avaliados o que indica que se pode substituir em até $30 \%$ a farinha de trigo por flocos de aveia.

A formulação com 30\% de flocos finos de aveia na massa de pizza apresentou boa aceitabilidade em relação aos atributos sensoriais aparência, aroma, sabor, textura e de uma forma geral, assim como a intenção de compra. Não teve um atributo especifico no qual os provadores mais gostaram, pois a nota média para cada um dos atributos investigados foi aproximadamente 8,0, mostrando que os julgadores gostaram igualmente de todos.

O resultado deste trabalho pode contribuir para o desenvolvimento de novos produtos para atender a expectativa de consumidores que busquem produtos com alto teor de proteína e qualidade sensorial e nutricional. As qualidades sensoriais do produto podem ter efeito bastante promissor no mercado, pois atendem à demanda do consumidor atual por produtos funcionais. 


\section{Agradecimentos}

Os autores agradecem ao Departamento de Engenharia de Alimentos e a Universidade Estadual do Centro-Oeste (UNICENTRO).

\section{Referências}

Alvim, I.D.; Fadini A.L.; Cruz C.L.C.V. Nutrição e Funcionalidade. In: Queiroz GC, Rego RA, Jardim DCP (Eds.) Brasil. Bakery \& Confectionery'Trends 2020. São Paulo, ITAL, 2014, p. 119-159.

Arango, H.G. Bioestatística teórica e computacional. 2a ed. Rio de Janeiro, Guanabara Koogan, 2005, p. 423.

Barbosa, L., Madi, L., Toledo, M.A., Rego, R.A. As Tendências da Alimentação. In: Moraes LC (Ed) Brasil. Food Trends 2020. São Paulo, ITAL, 2010, p.39-48.

Brasil. Ministério da saúde. Agência Nacional de Vigilância Sanitária - ANVISA. Resolução da Diretoria Colegiada - RDC n 93, de 31 de Outubro de 2000. Dispõe sobre o Regulamento Técnico para fixação de Identidade e Qualidade de Massa Alimentícia. DOU, 01/11/2000, Seção 1, p. 63.

Campos, C.R.; Santos, L.C.J.; Diniz, S.M.; Santos, J.A.B. Avaliação da Aceitabilidade da Pizza de Mix Integral Enriquecida com Três Grãos: Aveia, Linhaça e Quinoa. In: Simpósio Internacional de Inovação Tecnológica, Aracaju. Anais. 2014, p. 310-319.

Dutcosky, S.D.Análise Sensorial de Alimentos. $2^{a}$ edição, Curitiba, Editora Chapagnat, 2007, p. 239.

FDA. Food labeling. Health claims: oats and coronary disease. Federal Register, v. 62, n. 15, p. 3583-3601, 1997. Disponível em: < http://www.fda.gov/food/labelingnutrition/ labelclaims/healthclaimsmeetingsignificantscientificagreementssa/ucm074719.htm >. Acesso em: 13 de março de 2012.

Gutkoski, L.C.; Pedó, I.Aveia: composição química, valor nutricional e processamento. São Paulo: Varela. 2000, p. 191.

IAL - Instituto AdolfLutz. Normas Analíticas do Instituto Adolfo Lutz: Métodos químicos e físicos para análise de alimentos. 4a ed., ed. digital. São Paulo, 2008, p. 1020.

Larsen, D.M.; Seter, C.S.; Faubion, J.M. Effects of flour type and dough retardation time on the sensory characteristics of pizza crust. Cereal Chemistry. St.Luis, v. 70, n. 6, 1993, p. 647-650.

Mathewson, P. R. Enzymatic activity during bread baking. Cereal Foods World, v. 45, 
n. 3, 2000, p. 98-101.

Queiroz, G.C.; Rego, R.A.;Jardim,D.C.P.; Fadani, A.L.; Cruz, C.L.C.V.; Sarantópoulos, C.I.G.L.; Ruffi, C.R.G.; Nabeshima, E.H.; Vissotto, F.Z.; Dantas, F.B.H.; Montenegro, F.M.;Alvim, I.D.; Queiroz, M.B.; Augusto, P.P.C.; Luccas, V. As macrotendências dos setores de Bakery \& Confecttionery. In: Queiroz GC, Rego RA, Jardim DCP (Eds.) Brasil. Bakery \& Confectionery Trends 2020. São Paulo, ITAL. 2014, p. 61-73.

Russo, C.B.; Sostisso, C.F.; Pasqual, I.N.; Novello,D.; Dalla Santa, H.S.; Batista, M.G. Aceitabilidade sensorial de massa de pizza acrescida de farinhas de trigo integral e de linhaça (Linumusitatissimum L.) entre adolescentes. Revista Instituto Adolfo Lutz, v. 71, n. 3, 2012, p. 488-494.

Taco - Tabela Brasileira de Composição de Alimentos. 4. ed. Campinas: UNICAMP/ NEPA, 2011. p. 161.

Yougs, V.L.; Peterson, D.M.; Brown, C.M. Oats. In: POMERANZ,Y.Advances in cereal Science and Technology. Saint Paul, Minessota: AACC, 1985, v.5. 